\title{
Erratum to: Towards the Knowledge Society
}

João L. Monteiro ${ }^{1}$, Paula M.C. Swatman ${ }^{2}$, and Luis Valadares Tavares ${ }^{3}$

1 University of Minho, Portugal

2 University of Koblenz-Landau, Germany

3 Instituto Superior Técnico, Portugal

\section{Erratum to:}

\section{J.L. Monteiro et al. (Eds.) \\ Towards the Knowledge Society \\ DOI: $10.1007 / 978-0-387-35617-4$}

The book was inadvertently published with an incorrect name of the copyright holder. The name of the copyright holder for this book is: (c) IFIP International Federation for Information Processing. The book has been updated with the changes.

The updated original online version for this book can be found at DOI: $10.1007 / 978-0-387-35617-4$ 